\title{
Impact of Authentic Leadership on Work Engagement and Organizational Citizenship Behavior: The Meditating Role of Motivation for Work
}

Submitted 28/05/21, 1st revision 15/06/21, 2nd revision 18/07/21, accepted 10/08/21

Santiago Leal Paredes ${ }^{1}$, Jaime O. Salomón ${ }^{2}$, Jaime Rivera Camino ${ }^{3}$

\begin{abstract}
:
Purpose: The general purpose of this research was to analyze the effects of the perception of authentic leadership on work engagement and organizational citizenship behavior through motivation for work.

Design/Methodology/Approach: With a cross-sectional design, the data were obtained from 300 employees belonging to micro, small and medium-sized enterprises (MSMEs) in all the provinces of Ecuador, establishing causal relationships through regression and confirmatory factor analysis and supporting the structural equation model.

Findings: The results indicated support for previous studies and demonstrated that authentic leadership positively predicts work engagement and organizational citizenship behavior. Moreover, the findings revealed new insights into the positive and significant effects of authentic leadership on work engagement and organizational citizenship behavior through the satisfaction of needs for work motivation. The results revealed the importance of the perception of authentic leadership components among employees to satisfy needs for work motivation as a mediating variable of work engagement and organizational citizenship behavior as a driver of productivity in organizations.

Practical implications: Organization development professionals must carry out activities that facilitate strategies to satisfy needs as catalysts for the relationship between authentic leadership, work engagement, and organizational citizenship behavior.

Originality/value: This research provides new causal relationships between four constructs by analyzing leadership's direct and indirect effects.
\end{abstract}

Keywords: Authentic leadership, work engagement, motivation for work, organizational citizenship behavior.

JEL codes: M54, M12.

Paper type: Research article.

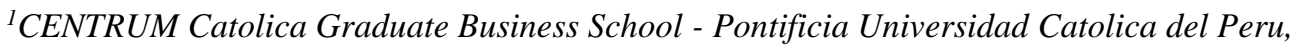
Lima,Peru,msleal@pucp.edu.pe;

${ }^{2}$ CENTRUM Catolica Graduate Business School - Pontificia Universidad Catolica del Peru,Lima,Peru,rjaime@pucp.pe;

${ }^{3}$ CENTRUM Catolica Graduate Business School - Pontificia Universidad Catolica del Peru,Lima,Peru,rjaime@pucp.pe; 


\section{Introduction}

Today, organizations face a competitive business environment in which managers, as leaders, must influence employees, respecting their feelings and work spirit, to obtain high performance, participation, and engagement (Šakić and Tandir, 2019). Leadership, defined as the behavior that a leader adopts to influence his or her followers and achieve the organization's goals, has been of interest to researchers to broaden the scientific community's knowledge.

The dimension of an ethical leader's moral personality refers to specific characteristics based on his or her credibility, honesty, and integrity (Gigol, 2020). The moral conduct of studying the leader's behavior has resulted from numerous ethical scandals involving prominent leaders of large organizations, multinational companies, political institutions, government organizations, and religious and non-profit associations to consider the principles and values that should guide the moral behavior of influential leaders based on their virtues (Brown and Treviño, 2006; Crawford et al., 2019; Gigol, 2020; Iqbal et al., 2018). Behaviors with adequate norms for interpersonal relationships among leaders and followers under a reward system and transparent communication represent indicators for the ethical dimension of the leadership conceptions that have emerged (Jordan et al., 2013).

In the last decade, there has been growing momentum for empirical research on authentic leadership (Baquero et al., 2019; Crawford et al., 2019; Gigol, 2020; Hu et al., 2018; Iqbal et al., 2018; Ribeiro et al., 2018), the dimensions of which have provided a relevant perspective on ethical leadership and performance in current organizations (Hassan et al., 2013; Leroy et al., 2015). Some authors have asserted that the research on authentic leadership derives from immoral behaviors resulting from the corruption that has caused scandals in various types of organizations (Iqbal et al., 2018). The loss of trust in leaders highlights the importance of leadership's ethical and moral aspects (Moriano et al., 2011). Both public and private organizations have experienced highly publicized corporate scandals, including mismanagement, which have contributed to the need for authenticity and authentic leadership (Walumbwa et al., 2008).

The theory of authentic leadership bases the leader's moral behavior in decision making on high levels of self-awareness and the establishment of transparent relationships with followers to achieve optimal performance (Avolio and Gardner, 2005). Some authors have suggested conducting studies on authentic leadership in the framework of new and small enterprises to determine how entrepreneurs can more fully exploit potential growth opportunities (Jensen and Luthans, 2006). In addition, studies have shown that authentic leadership produces positive effects in the area of working life (Banford et al., 2012) because, through the characteristics of authentic leadership, employees develop positive attitudes toward their work and perceive that their leaders show an interest in the professional development of their employees (Hassan and Ahmed, 2011). 
Recently, other authors have pointed out a lack of empirical research investigating how leadership in MSMEs drives the processes of creating new products through engagement (Belitski and Liversage, 2019). Similarly, it has been suggested that studies should address the effects of authentic leadership on work engagement (Gigol, 2020; Rahmadani et al., 2020), motivation for work through the satisfaction of needs (Gill et al., 2018), and organizational citizenship behavior (Iqbal et al., 2018; Joo and Jo, 2017; Zubair and Khan, 2018) among organizations' employees. In this sense, the objective of this research was to analyze the influence of the perception of authentic leadership on work engagement and organizational citizenship behavior through motivation for work. In this area, the following specific objectives were established: (1) to determine how the perception of authentic leadership's components influences work engagement; (2) to establish the influence of the perception of authentic leadership's components on motivation for work; (3) to analyze the influence of the perception of authentic leadership's components on organizational citizenship behavior; (4) to identify the influence of work engagement on organizational citizenship behavior; (5) to examine the influence of motivation for work on organizational citizenship behavior; and (6) to describe the influence of motivation for work on work engagement.

\section{Literature Review}

\subsection{Authentic Leadership}

Authenticity in leaders is based on five characteristics: (1) pursuing purpose with passion; (2) practicing strong values; (3) leading with a whole heart; (4) establishing lasting relationships; (5) demonstrating self-discipline (George, 2003). Authentic leadership is considered the central nucleus of other forms of positive leadership. It can incorporate transformative, charismatic, service, spiritual, or other forms of effective leadership (Avolio and Gardner, 2005). It adopts characteristics of honesty, integrity, and loyalty ( $\mathrm{Hu}$ et al., 2018), and it instills ethical behavior in followers, differentiating itself from ethical leadership (Moriano et al., 2011).

Authentic leaders are individuals who know who they are, what they think and how they behave and who are perceived by others as being aware of their values and the moral perspective, knowledge, and strengths of others, being aware of the context in which they operate and being confident, hopeful, resilient and of high moral character (Avolio et al., 2004). They avoid behaving inconsistently and hiding their ideas and emotions, even when these could be uncomfortable for followers (Luthans and Avolio, 2003). Gardner et al. (2005) established a model of authentic leadership development and authentic followers from previous references (Luthans and Avolio, 2003). In general terms, the authors argued that the authenticity of the leader is based on his or her personal experiences (Harter, 2002), on the nature of the optimization of selfesteem, characterized by high, genuine, authentic, stable and congruent self-esteem, through the components of authenticity-awareness, impartial, action and relational 
processing (Kernis, 2003) and on the well-being that occurs among leaders and followers (Ilies et al., 2005).

Authentic leadership is defined as a process that is nourished by individual capacities, which, described in positive psychology, includes a positive moral perspective, characterized by the presence of high moral standards that guide behavior and the decision-making process of leaders in highly developed and efficient organizational contexts (Luthans and Avolio, 2003). For this reason, authentic leaders are individuals who are deeply aware of their values and beliefs, of how they behave, and, in turn, of how they are perceived by others (Shamir and Eilam, 2005). The conceptualization of this type of leadership, as carried out by Walumbwa et al. (2008), considers its components by distinguishing authentic leadership as a pattern of the leader's behavior that is based on and fosters positive psychological capacities and a positive ethical climate to promote greater self-awareness, an internalized moral perspective, balanced information processing and relational transparency among leaders working with followers, encouraging positive self-development. This definition of authentic leadership has prevailed in empirical research (Crawford et al., 2019; Edú-Valsania et al., 2012; Giallonardo et al., 2010; Gigol, 2020; Gill et al., 2018; Hsieh and Wang, 2015; Iqbal et al., 2018; Leroy et al., 2012; Liu et al., 2018; McAuliffe et al., 2019; Moriano et al., 2011; Oh et al., 2018; Ribeiro et al., 2018; Wang and Hsieh, 2013).

Following the theoretical approaches of other authors, Walumbwa et al. (2008) distinguished four components of authentic leadership, noting that they are different but related substantive elements. The first component is awareness of oneself, or selfawareness, based on the display of strengths and weaknesses to obtain recognition of the leader's impact on the followers (Kernis, 2003). The second component is relational transparency, which refers to promoting trust through appropriate emotions and information about thoughts (Kernis, 2003). The third component is balanced information thinking, which consists of the objective analysis of data before making a decision based on the requirements of other points of view (Gardner et al., 2005). The fourth component is the internalized moral perspective, which describes a behavior based on internal moral standards and values (Avolio and Gardner, 2005).

\subsection{Work Engagement}

It should be clarified that the terms "employee engagement" and "work engagement" have been used interchangeably in research. Schaufeli (2013) distinguished work engagement as the term that should be used to express an employee's relationship with his or her work, while employee engagement may also include the relationship with the organization.

From the most general perspective, in the literature, there are two different schools of thought or two streams of research that provide engagement models (Saks, 2006). The first is based on the psychological conditions of personal engagement and disconnection at work (Kahn, 1990). It characterizes work engagement in three basic 
dimensions, energy, participation, and effectiveness, which are the dimensions that are precisely opposite to burnout, whereby energy becomes exhaustion, involvement becomes cynicism, and efficacy becomes ineffectiveness (Maslach and Leiter, 1997). The second is stated as the alternative view on the study of work engagement (Bakker et al., 2008). However, it is consistent with the statement that work engagement is the positive antithesis of burnout, considers burnout and work engagement as opposite concepts that must be measured independently with different instruments (Schaufeli et al., 2002). This model indicates that burnout implies the erosion of work engagement (Saks, 2006), it is the dark side of work engagement (Schaufeli and Salanova, 2011).

Work engagement is conceptualized as a positive, effective-motivational high-energy state combined with high dedication and a strong focus on absorption at work (Schaufeli and Bakker, 2010). However, many empirical studies have considered the definition of work engagement as a positive, satisfying, and work-related state of mind characterized by vigor, dedication, and absorption (Schaufeli et al., 2002). The concept of work engagement indicates three factors that characterize employees' behavior: vigor denotes high levels of energy, effort, and persistence in the face of difficulties at work; dedication means being firmly involved in work (Schaufeli et al., 2002), showing feelings of importance, enthusiasm, inspiration, pride and challenge (Schaufeli et al., 2006), and absorption refers to a pleasant state of total immersion in work, marked by the time that passes quickly and the inability to separate oneself from work (Schaufeli, 2018; Schaufeli et al., 2002; 2006).

\subsection{Organizational Citizenship Behavior}

Organ (1988), who is generally considered to be the father of organizational citizenship behavior (OCB) (Zubair and Khan, 2018), conceptualized organizational citizenship behavior as individual behavior that is discretionary, not directly or explicitly recognized by the formal system of rewards and promotes the efficient and effective functioning of the organization (Organ, 1988; 2018). This definition includes several features of organizational citizenship behavior. The first refers to discretion, which denotes that this behavior is not formally required as part of the job description. The second indicates that it is not directly or formally rewarded by the organization, that is not established legally or contractually, although it could represent non-tangible benefits to the worker. The third reflects the need for behavior, as a whole and over time, to contribute to organizational effectiveness and consistent results over time (Organ, 1988).

Organizational citizenship behavior is voluntary individual behavior (Edú-Valsania et al., 2012), related to the activities performed by employees and exceeds the formal requirements of their position, contributing to the effective functioning of the organization (Finkelstein and Penner, 2004). Depending on the origin of organizational citizenship behavior, two dimensions of the construct have been distinguished: organizational citizenship behavior directed to individuals (OCBI) and 
organizational citizenship behavior directed to the organization (OCBO) (McNeely and Meglino, 1994).

Organizational citizenship behavior directed to individuals refers to actions carried out by employees that are aimed at helping colleagues and have indirect implications for the benefits for the organization (Lee and Allen, 2002), they are prosocial behaviors directed to specific people within the organization focused on helping the employees with work or personal problems (Edú-Valsania et al., 2012). Organizational citizenship behavior directed to the organization consists of deliberate actions in which the employee collaborates with the functions related to work to obtain a benefit for the organization (Lee and Allen, 2002), these actions are preferably directed to the benefit of the organization as a whole (Edú-Valsania et al., 2012) and refer to the prosocial behaviors of additional roles intended only to contribute to the organization (McNeely and Meglino, 1994).

\subsection{Motivation for Work}

Motivation for work or work motivation is defined as the energetic forces that originate and drive the form, direction, intensity, and duration of work-related behavior in an employee (Pinder, 2008). A worker's motivation is the result of interactions with his or her work environment, in which structures, resources, the organizational culture, and feedback contribute to the motivational processes that occur at the individual level (Franco et al., 2002).

The hierarchy of needs theory (Maslow, 1954, 1991) defines motivation as a process that starts with the needs of physiology and psychology that drive behaviors or stimuli leading to goals or incentives. This process awakens, energizes, directs, and sustains employee behavior within an organization (Luthans, 2002). Motivation is based on the idea that individual needs or expectations result in behavior or action that drives an individual to achieve the desired goals, providing satisfaction for him- or herself (Kuranchie-Mensah and Amponsah-Tawiah, 2016). Motivation is composed of three interdependent elements that interact with one another, the needs that appear when a physiological or psychological imbalance arises, the impulses, also called motives, that are the means that serve to alleviate the needs and the incentives that intervene to alleviate a need or reduce an impulse (Luthans, 2002). The starting point of the theories on motivation is needed; therefore, motivation for work is considered the driving force to pursue and satisfy needs (Malik et al., 2018).

Motivation for work continues to be one of the sensitive issues that determine the level of contribution that employees will put into the organization to engage with good performance, and this is why managers of organizations must know the needs of their employees to find out what motivates them (Kuranchie-Mensah and AmponsahTawiah, 2016). According to Sashkin (1996), there are four categories of employee needs that help determine work motivation. The first category of motivation for work contains protection and security needs related to stability in job security, income, and 
a retirement and health insurance plan. The social and belonging needs correspond to the second category of work motivation, including employees' need for social relationships within their work environment. The third category of motivation is based on self-esteem needs driven by a high salary, self-worth, and recognition of and respect for performance. Finally, self-actualization needs are in the fourth category of motivation for work, these are linked to happiness, learning, and personal development.

\section{Relationships Between Variables and Research Hypotheses}

\subsection{Relationship Between Authentic Leadership and Work Engagement}

The literature review on the relationship between authentic leadership and work engagement indicated the requirement for a model focused on the process mechanisms through which authentic leaders influence employees' positive attitudes and behaviors (Avolio et al., 2004). A study to identify the research on authentic leadership, the areas of work-life and work engagement established that the areas of work-life completely mediate the relationship between authentic leadership and work engagement. However, the findings also showed that the four components that characterize a true leader positively correlate with work engagement (Banford et al., 2012).

Another study on the perception of authentic leadership, work engagement, and job satisfaction proposed that authentic leadership creates an authentic connection that fosters employee engagement. The findings revealed that work engagement partially mediates the relationship between authentic leadership and job satisfaction and that authentic leadership is positively related to work engagement, concluding that the development of a relationship between an authentic leader and his or her followers is essential for work engagement (Giallonardo et al., 2010). Similarly, other findings have confirmed that the influence of authentic leadership generates higher levels of work engagement and dedication at work (Wong et al., 2010).

Wang and Hsieh (2013) examined the relationships between authentic leadership, employee trust, and employee work engagement and showed that leader authenticity is positively related to employee confidence, which is undoubtedly related to work engagement. Subsequently, the same authors confirmed that consistency in the action of authentic leadership promotes trust between the leader and the employees, which further improves employees' work engagement (Hsieh and Wang, 2015). Last, a recent study on large companies in South Korea confirmed that the authentic leadership of Korean corporate leaders has a significantly positive effect on followers' work engagement (Oh et al., 2018). All the research mentioned above has signaled that there is a positive relationship between authentic leadership and work engagement; hence, the following research hypothesis is proposed:

\section{H1: Authentic leadership and work engagement are positively related.}




\subsection{Relationship between Authentic Leadership and Motivation for Work}

The relationship between authentic leadership factors and the satisfaction of needs as categories of work motivation has been evidenced in empirical research. Some authors have distinguished work motivation as a predictor of performance, relational, and well-being results (Ryan and Deci, 2000). With a conceptual model and an ontological definition of authentic leadership, rooted in two distinct yet related philosophical approaches to human well-being-hedonism and eudemonia-the positive influence of the authentic leadership components on the satisfaction of the followers' needs has been verified (Ilies et al., 2005). Another study supported this research that provided, with a sample of 30 leaders and 252 followers in 25 Belgian service companies, evidence that authentic leadership is positively related to the satisfaction of the followers' basic needs (Leroy et al., 2012).

Another investigation verified the hypothesis that the presidents of the boards of directors of a Canadian credit union with an authentic leadership style favor motivation. The study validated the hypothesis that presidents with an authentic leadership style favor motivation and engagement through a participatory security climate based on transparency and the exchange of ideas (Guerrero et al., 2014). Other results have supported the argument that managers who display authentic leadership behaviors can strengthen the satisfaction of employees' needs in a human resource system through their interpersonal qualities (Gill et al., 2018). These studies have shown that authentic leadership behavior leads to motivation for work; thus, the following hypothesis is raised:

\section{H2: Authentic leadership and motivation for work are positively related.}

\subsection{Relationship Between Authentic Leadership and Organizational Citizenship Behavior}

Most of the empirical research that has examined the relationship between organizational citizenship behavior and leadership has produced significant effects (Organ et al., 2006). Research has revealed that those employees who experience more honest and trusting relationships with their supervisors display higher levels of organizational citizenship behavior (Mayer and Gavin, 2005).

The literature review identified a study that examined the effect of authentic leadership behavior on followers' organizational citizenship behavior. It demonstrated that authentic leadership was significantly related to organizational citizenship behavior and concluded that the more leaders are considered authentic, the more employees identify with them, feel psychologically empowered, become more involved in their roles (Walumbwa et al., 2010).

Similarly, research has analyzed the effect of authentic leadership on employees' organizational citizenship behavior. The focus has been specifically on the 
relationships of the four components of authentic leadership, and it has shown that authentic leadership positively affects employees' organizational citizenship behavior but in different ways. Behaviors directed to individuals are only significantly affected by relational transparency, while behaviors directed to the organization are affected by both moral and relational transparency, although the latter has a more significant impact (Edú-Valsania et al., 2012).

Another study, conducted in the oil sector in the United Arab Emirates, revealed that authentic leadership significantly increases work engagement and organizational citizenship behavior (Al Sahi et al., 2016). In this sense, authentic leaders are expected to promote more prosocial organizational behaviors among their followers; hence, the basis for the following hypothesis is formed:

H3: Authentic leadership and organizational citizenship behavior are positively related.

\subsection{Relationship Between Work Engagement and Organizational Citizenship Behavior}

Recent research has indicated that work engagement is a consistent and robust predictor of organizational citizenship behavior; therefore, those investigations have suggested conducting studies that generate conclusions regarding the causal associations between work engagement and organizational citizenship behavior $(\mathrm{Xu}$ et al., 2019). Higher levels of engagement promote higher levels of organizational citizenship behavior (Wahyu, 2013), a sense of personal initiative, and proactive behavior (Salanova and Schaufeli, 2008).

Considering that employees have high energy levels and mental recovery capability, and hence are willing to invest effort and persist in their work (Zhang et al., 2017) and that work engagement is a positive attitude that an employee has toward the organization with which he or she can improve the organizational citizenship behavior (Wahyu, 2013), the following hypothesis can be inferred:

H4: Work engagement and organizational citizenship behavior are positively related.

\subsection{Relationship Between Motivation for Work and Organizational Citizenship Behavior}

Research has suggested that motivation for work is significantly related to organizational citizenship behavior (Finkelstein and Penner, 2004). Employees choose to participate in organizational citizenship behavior because they satisfy their own needs as motivating factors and allow them to achieve the desired results (Rioux and Penner, 2001). Barbuto and Story (2011) evaluated the relationship between the sources of work motivation and their demonstration of organizational citizenship behavior. The results reflected significant positive relationships between the internal 
motivations of the individuals' self-concept and the organizational citizenship behavior. However, the results also showed significant negative relationships between instrumental and self-concept external motivations and organizational citizenship behavior (Barbuto and Story, 2011). Nevertheless, other studies have shown that work motivation contributes to organizational citizenship behavior (Gerhart and Fang, 2014). From these findings, the following hypothesis is constructed:

H5: Motivation for work and organizational citizenship behavior are positively related.

\subsection{Relationship Between Motivation and Work Engagement}

Studies on the relationship between motivation for work and work engagement have offered findings with implications for pragmatic, statistical, substantive, and intervention considerations in research (Martin, 2008). Empirical studies have provided results supporting the claim that primary motivation is an impetus for work engagement. In this sense, some authors have linked motivation for work and work engagement in a single concept and have explained that motivation is defined as the relevant inclination, energy, emotion, and drive to learn, work effectively and achieve engagement, distinguished as the behaviors that reflect this inclination, energy, emotion, and drive (Martin et al., 2017).

Other studies have confirmed that employees with high intrinsic motivation take on the greater responsibility offered and exhibit the willingness required by the organization when performing and thus demonstrate their work engagement when they have internalized the structure and rules that surround their roles and obligations at work (Dysvik and Kuvaas, 2011). Research has reported job security, retirement plan, and health insurance as determining factors of motivation that directly affect work engagement (Kuranchie-Mensah and Amponsah-Tawiah, 2016).

Maslach and Leiter (2008) associated burnout with responses to work. Positive responses are in the form of engagement toward motivation, and negative ones are in the form of job dissatisfaction, absenteeism, an intention to leave work, turnover, and stress. The authors demonstrated that some motivation factors for work, such as reward and recognition, reflect the approach to employee work engagement (Maslach and Leiter, 2008). With the support of the investigations into the mentioned constructs, the following hypothesis can be suggested:

H6: Motivation for work and work engagement are positively related.

\subsection{Relationship Between Authentic Leadership, Motivation to Work, Work Engagement, and Organizational Citizenship Behavior}

The literature review makes it possible to point out the relationship between authentic leadership, motivation for work, work engagement, and organizational citizenship 
behavior. Authentic leadership is presented as an emerging leadership model (Luthans and Avolio, 2003) in which the basic construction that creates the conditions for greater confidence helps people to develop their strengths and be more positive, expand their thinking, add value and understand what is suitable for their decisions (Avolio et al., 2004). Studies have shown positive effects of authentic leadership on work engagement (Giallonardo et al., 2010; May et al., 2004; Oh et al., 2018; Walumbwa et al., 2010; Wang and Hsieh, 2013), motivation for work (Gill et al., 2018; Guerrero et al., 2014; Leroy et al., 2015; Walumbwa et al., 2008) and organizational citizenship behavior (Al Sahi et al., 2016; Edú-Valsania et al., 2012; Walumbwa et al., 2010).

Some authors have explained that organizational citizenship behavior has been explored and investigated by academics for more than two decades and continues to be a high priority because it has a positive impact on organizational success through the motivation for work produced by the satisfaction of labor needs, engagement and leader behavior (Xu et al., 2019). Employees choose to participate in organizational citizenship behavior because they satisfy their own needs as motivating factors and allow them to achieve the desired results (Rioux and Penner, 2001). Research has revealed that motivation mediates the relationship between perceived training opportunities and organizational citizenship behavior (Dysvik and Kuvaas, 2011).

An employee's motivation for work is based on his or her willingness to exercise and maintain an effort to achieve the organization's objectives (Franco et al., 2002). It is a process produced by an impulse that awakens, energizes, directs, and sustains behavior (Luthans, 2002). This impulse dynamizes the activities (Pinder, 2008), it is produced by a need that indicates an action (Olafsen et al., 2018). When the impulse that behavior produces in an employee is characterized by a positive energetic, mental state that indicates vigor, a motive that indicates dedication, and a cognitive component that indicates absorption (Schaufeli et al., 2002), the employee reflects his or her work engagement and that vigor denotes his or her motivation to face difficulties at work (Maunno et al., 2007).

When the behavior is characterized by the inclination to help, competitive spirit, organizational loyalty, organizational compliance, individual initiative, civic virtue, and self-development (Podsakoff et al., 2000), it can be understood as an individual behavior of obedience or organizational compliance that denotes organizational citizenship behavior (Organ et al., 2006; Zubair and Khan., 2018).

After describing the relationships between the four constructs that support this study, it is presumed that the effects of the perception of authentic leadership factors influence work engagement and organizational citizenship behavior through motivation for work. The following general hypothesis that supports the investigation is inferred: 
GH: The perception of authentic leadership directly and positively influences work engagement and organizational citizenship behavior through motivation for work.

Addressing the research hypotheses, the conceptual model of the research is presented in Figure 1.

Figure 1. Conceptual model

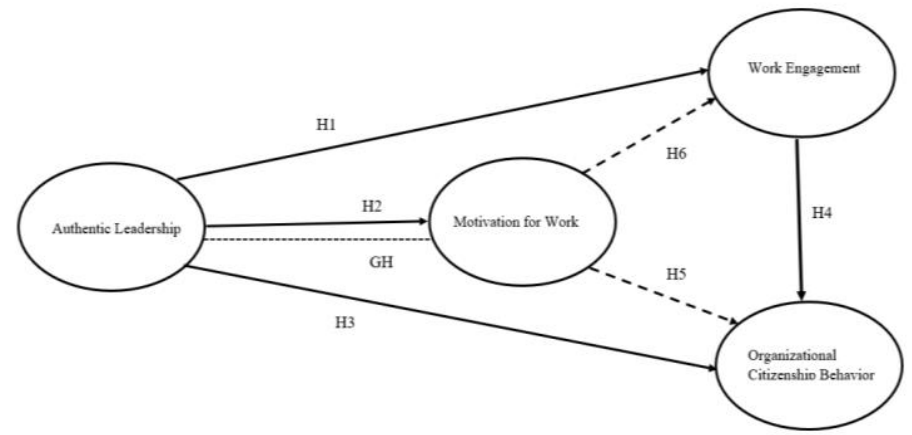

Source: Own study.

\section{Methodology and Data}

The conceptual model of the research evaluates the hypothetical relationships among the constructs by applying the model of structural equations, which helps to analyze a theoretical framework from a prediction perspective to understand and explore the existing theories (Hair et al., 2018).

In Ecuador, the Instituto Nacional de Estadísticas y Censos (INEC) has designed the Directorio de Empresas y Establecimientos (DIEE) based on the Instituto Ecuatoriano de Seguridad Social (IESS) and the Servicio de Rentas Internas (SRI). The study selected the latest information from the INEC, which distinguishes a total of 83,527 micro, small and medium enterprises (MSMEs) corresponding to all economic sectors with multiple activities in 2019; these have been growing year after year in the country and, in specific sectors of the economy, are the most critical group in terms of profit, sales income, employment and number of enterprises. Therefore, their analysis is relevant, mainly since they account for 1'783,852 employees in the provinces of Ecuador.

Medium companies in Ecuador are defined by the annual sales volume between USD 1'000,001 to USD 5'000,001 and from 50 to 200 workers, while small companies have annual sales between USD 100,001 to USD 1'000,000, and from 10 to 49 workers, the micro-enterprises will have annual sales less than or equal to USD 100,000 and from 1 to 9 workers (DIEE, 2019), as presented in detail in Table 1. To address the purposes of the study, information was collected personally by the researcher over three months; assuring the privacy and confidentiality of the workers; data were obtained from employees regarding their different characteristics or socio-biographical control 
variables, including gender, age, marital status, education, nationality, and time in the organization, which identified their representation in the sample.

Table 1. Population of MSMEs and employees in Ecuador

\begin{tabular}{cccccc}
\hline \multicolumn{4}{c}{ Micro, small, and medium enterprises in Ecuador } \\
\hline \multicolumn{2}{c}{ Micro } & \multicolumn{2}{c}{ Small } & \multicolumn{2}{c}{ Medium } \\
\hline Enterprises & Employees & Enterprises & Employees & Enterprises & Employees \\
\hline 27,620 & 738,220 & 44,314 & 534,844 & 11,593 & 510,788 \\
\hline
\end{tabular}

Source: Data obtained from the report of the Directorio de Empresas y Establecimientos (Directory of Enterprises and Establishments) in November 2019.

\subsection{Measurements}

The literature review made it possible to analyze and identify the different measurement instruments for the four study variables and to request the respective authorization for their application from the authors.

Authentic leadership: To measure the behavior of this construct, the Authentic Leadership Questionnaire (ALQ), prepared by Walumbwa et al. (2008), was used. This instrument was translated into Spanish and validated by Moriano et al. (2011) and has already been applied and tested in several investigations in Spanish-speaking countries. The questionnaire is made up of 16 items corresponding to four factors: (1) relationship transparency (five items, for example, "My leader encourages each person to express their opinion"); (2) internalized morality (four items, for example, "He/she shows beliefs that are consistent with his/her actions"); (3) balanced processing (three items, for example, "He/she analyzes relevant data before reaching a decision"); and (4) self-awareness (four items, for example, "He/she has a fairly accurate idea of how other people assess his/her leadership abilities"). The questionnaire uses a Likert frequency scale from 1 to $5: 1$ = "never"; 2 = "hardly ever"; 3 = "sometimes"; 4 = "very often"; and 5 = "always."

Work Engagement: The Scale of Engagement at Work or Utrecht Work Engagement Scale (UWES) by Schaufeli and Bakker (2010) was used. This instrument has been translated into Spanish and has been tested and used in several studies. It reflects people's feelings at work. The 17-item questionnaire assesses three factors: (1) vigor (six items, for example, "In my job, I feel full of energy"); (2) dedication (five items, for example, "I am enthusiastic about my job"); and (3) absorption (six items, for example, "Time flies when I am working"). The questionnaire uses a Likert frequency scale from 1 to 5: 1 = "never"; 2 = "hardly ever"; 3 = "sometimes"; 4 = "very often"; and 5 = "always."

Organizational citizenship behavior: This variable was evaluated using the questionnaire designed by Lee and Allen (2002) based on the constructs by McNeely and Meglino (1994) and Williams and Anderson (1991), which was adapted, 
translated, and validated in Spanish by Dávila and Finkelstein (2010). It has been used in several studies. The 16-item questionnaire assesses two factors or dimensions: (1) organizational citizenship behavior directed to individuals (eight items, for example, "Assisting others with their duties"); and (2) organizational citizenship behavior directed to the organization (eight items, for example, "Defend the organization when other employees criticize it"). The questionnaire uses a Likert frequency scale from 1 to $5: 1$ = "never"; 2 = "hardly ever"; 3 = "sometimes"; 4 = "very often"; and $5=$ "always."

Motivation for work: This variable was evaluated with 20 items from the MbM questionnaire, prepared by Sashkin (1996) to measure the categories of motivation at work and published in Spanish, which has been validated in different studies. This variable was operationalized in four dimensions: (1) protection and security needs (five items, for example, "For me, it is essential to be able to have a regular income"); (2) social and belonging needs (five items, for example, "Being part of a united working group is very important to me"); (3) self-esteem needs (five items, for example, "My achievements give me an important sense of self-respect"); and (4) selfactualization needs (five items, for example, "I would rather do things that I know how to do well than try to do new things"). The questionnaire uses a Likert frequency scale from 1 to $5: 1$ = "never"; 2 = "hardly ever"; 3 = "sometimes"; 4 = "very often"; and $5=$ "always."

Socio-biographical control variables: In the data collection instrument, reference is made to variables that, in addition to stratifying the sample, help to obtain data on employees: gender, age, marital status, educational level, nationality, and time in the company. Over three months, these data were personally collected by the researcher. One of the advantages of this type of data collection is that the researcher can explain questions and tasks much more complete than when using self-administered questionnaires (Fowler, 2014). For data analysis, the IBM SPSS V23 AMOS software was used.

\subsection{Data Analysis}

Based on the recommendations made by some authors regarding the sample for analysis with a structural equation model (Barrett, 2007; Kline, 2016), the study used a simple random sample of 300 employees, in which each employee population has the same likelihood of being selected (Creswell and Creswell, 2018). First, confirmatory factor analysis was performed to evaluate the validity and reliability of each construct in the measurement instrument. Second, a descriptive statistic and a correlation analysis among the variables were performed. Third, a structural equation model was employed to estimate the model's fitness and the trajectory coefficient and measure the mediation effect. For data analysis, the IBM SPSS V23 AMOS software was used. 


\section{Results}

The descriptive analysis revealed the main sociodemographic characteristics of the subjects in the sample used. Table 2 shows the results of the socio-biographical control variables, including gender, age, marital status, education, nationality, and time in the organization.

Table 2. Sociodemographic characteristics

\begin{tabular}{|c|c|c|c|}
\hline Characteristic & Description & Frequency & Percentage \\
\hline \multirow{2}{*}{ Gender } & Female & 101 & $34 \%$ \\
\hline & Male & 199 & $66 \%$ \\
\hline \multicolumn{2}{|c|}{ Total } & 300 & $100 \%$ \\
\hline \multirow{3}{*}{ Age } & From 18 to 30 years old & 115 & $38 \%$ \\
\hline & From 31 to 45 years old & 118 & $39 \%$ \\
\hline & Over 50 years old & 67 & $24 \%$ \\
\hline \multicolumn{2}{|c|}{ Total } & 300 & $100 \%$ \\
\hline \multirow{4}{*}{ Marital status } & Single & 127 & $42 \%$ \\
\hline & Married & 144 & $48 \%$ \\
\hline & Widow(er) & 7 & $3 \%$ \\
\hline & Divorced & 22 & $7 \%$ \\
\hline \multicolumn{2}{|c|}{ Total } & 300 & $100 \%$ \\
\hline \multirow{3}{*}{ Education } & Elementary school & 67 & $23 \%$ \\
\hline & High school & 148 & $49 \%$ \\
\hline & Higher education & 85 & $28 \%$ \\
\hline \multicolumn{2}{|c|}{ Total } & 300 & $100 \%$ \\
\hline \multirow{2}{*}{ Nationality } & Ecuadorian & 196 & $65 \%$ \\
\hline & Foreign & 104 & $35 \%$ \\
\hline \multicolumn{2}{|c|}{ Total } & 300 & $100 \%$ \\
\hline \multirow{5}{*}{ Time in the enterprise } & Less than 1 year & 56 & $19 \%$ \\
\hline & Between 1 and 3 years & 116 & $39 \%$ \\
\hline & Between 3 and 6 years & 81 & $27 \%$ \\
\hline & Between 6 and 10 years & 33 & $10 \%$ \\
\hline & Over 10 years & 14 & $5 \%$ \\
\hline \multicolumn{2}{|c|}{ Total } & 300 & $100 \%$ \\
\hline
\end{tabular}

Source: Created by the authors using the results from the study.

In the exploratory analysis, for evaluating multivariate atypical data, statistical methods based on distances were used-the Mahalanobis distance $\left(\mathrm{D}^{2}\right)$ and Cook's distance-and the results showed the absence of outliers.

The results obtained to establish the normality of the variables in terms of the asymmetry range between -2.031 and 1.889 and those for kurtosis range between 1.461 and 3.744 , indicating that the data comply with the assumption of multivariate normal distribution, which establishes common asymmetry values $<3$ and standard kurtosis values < 10 (Kline, 2016). Likewise, multivariate normality was evaluated through the Mardia coefficient (Byrne, 2010), obtaining values $<70$ for each variable, indicating the multivariate normality of the data. The means, standard deviation, and correlations of all the variables examined are shown in Table 3. The correlations vary between 0.4 and 0.7 . They are also statistically significant. 
Table 3. Measurements, standard deviation and correlation

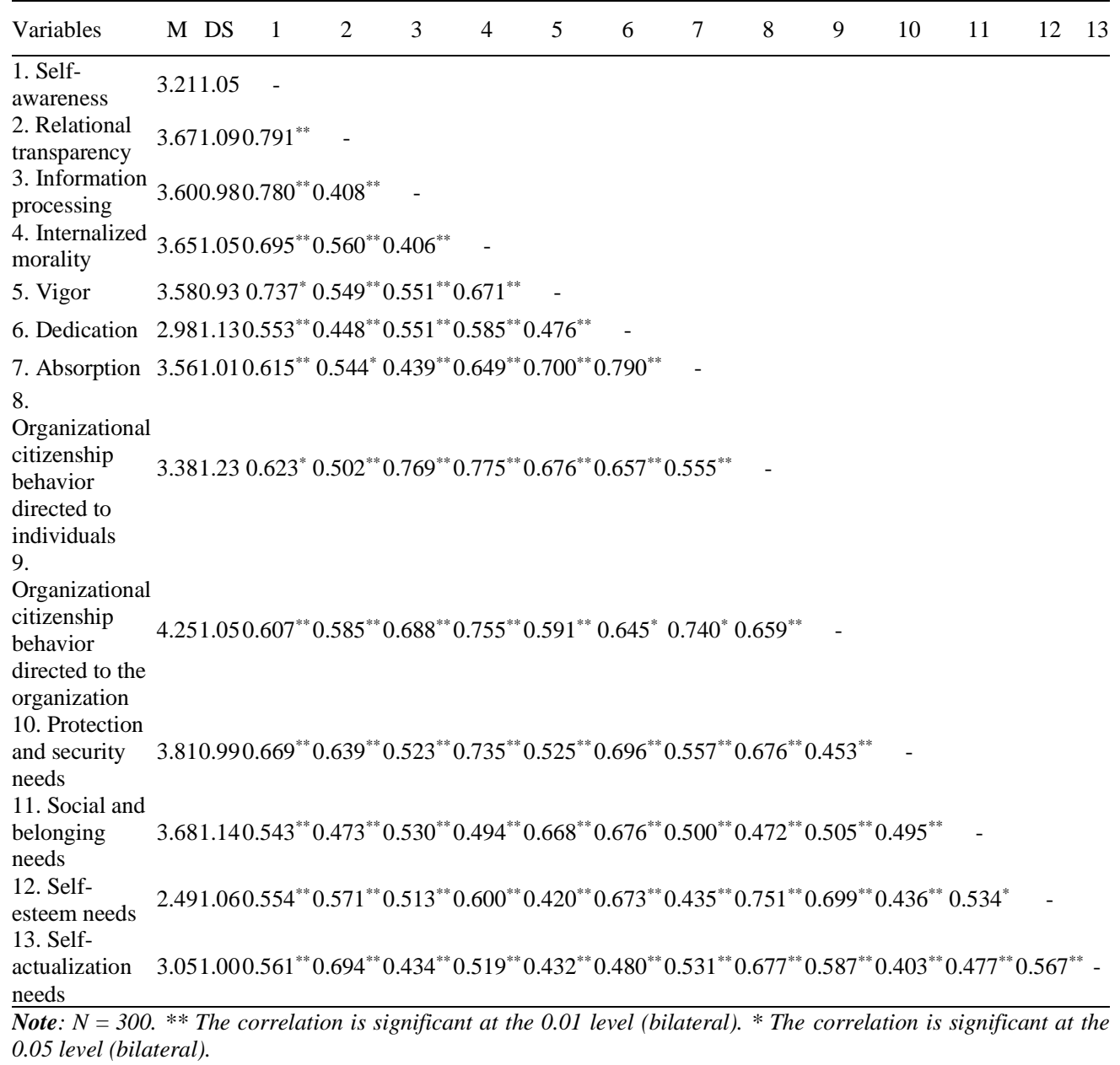

Source: Created by the authors using the results from the study.

\subsection{Reliability and Validity}

Table 4 shows the reliability after assessing the convergence of each of the constructs. The Alpha coefficients are between 0.65 and 0.83 , which is considered to be an acceptable and adequate level of reliability (Bagozzi and Yi, 1988; DeVellis, 2017; Green et al., 1977; Taber, 2018; Ursachi et al., 2015), thus providing additional support for the acceptable reliability of the constructs.

Table 4. Validity and reliability of the instruments

\begin{tabular}{cccc}
\hline Instrument dimensions & Alpha & $\begin{array}{c}\text { Composite } \\
\text { reliability }\end{array}$ & $\begin{array}{c}\text { Average variance } \\
\text { extracted }\end{array}$ \\
\hline Self-awareness & 0.667 & 0.691 & 0.465 \\
Relational transparency & 0.779 & 0.867 & 0.626 \\
Balanced information processing & 0.772 & 0.775 & 0.535
\end{tabular}




\begin{tabular}{clll} 
Internalized morality & 0.760 & 0.764 & 0.552 \\
\hline Vigor & 0.650 & 0.620 & 0.468 \\
Dedication & 0.725 & 0.705 & 0.539 \\
Absorption & 0.770 & 0.769 & 0.536 \\
\hline $\begin{array}{c}\text { Organizational citizenship behavior } \\
\text { directed to individuals }\end{array}$ & 0.814 & 0.815 & 0.669 \\
\hline $\begin{array}{c}\text { Organizational citizenship behavior } \\
\text { directed to the organization }\end{array}$ & 0.707 & 0.708 & 0.581 \\
\hline Protection and security needs & 0.702 & 0.696 & 0.471 \\
Social and belonging needs & 0.782 & 0.790 & 0.566 \\
Self-esteem needs & 0.833 & 0.844 & 0.649 \\
Self-actualization needs & 0.715 & 0.709 & 0.528 \\
\hline
\end{tabular}

Source: Created by the authors using the results from the study.

Exploratory factor analysis (EFA) was applied to determine the validity of the questionnaires. It is the quintessential technique used to explore the set of latent variables or common factors that explain the responses to the items of a test (LloretSegura et al., 2014). Convergent validity is admitted if each observation presents statistically significant factor loadings (the coefficients must be greater than twice their standard error) in the variable construct that it is supposed to be measuring (Hair et al., 2018). Evidence of convergent validity is noted; that is, most of the factor loadings are above 0.50 .

To demonstrate the discriminant validity reflected in Table 5, a comparison of the restricted and unrestricted models was undertaken. The difference between the two models allowed us to confirm the discriminant validity, which indicates that the differences are statistically significant and infers that each of the dimensions measures different factors.

Table 5. Restricted and unrestricted models for the discriminant validity of the constructs

\begin{tabular}{|c|c|c|c|}
\hline & Chi squared & Differences & \\
\hline Authentic leadership & $\begin{array}{c}\text { Unrestricted } \\
\text { model } \\
(8 \mathrm{GL})\end{array}$ & $\begin{array}{l}\text { Restricted model } \\
\quad(9 \text { GL) }\end{array}$ & \\
\hline $\begin{array}{l}\text { Self-awareness vs relational } \\
\text { transparency }\end{array}$ & 33.9 & 51.5 & 17.6 \\
\hline $\begin{array}{l}\text { Self-awareness vs balanced } \\
\text { information processing }\end{array}$ & 33.4 & 37.9 & 4.5 \\
\hline $\begin{array}{c}\text { Self-awareness vs internalized } \\
\text { morality }\end{array}$ & 71.4 & 87.4 & 16 \\
\hline $\begin{array}{l}\text { Relational transparency vs balanced } \\
\text { information processing }\end{array}$ & 40.3 & 60.2 & 19.9 \\
\hline $\begin{array}{l}\text { Relational transparency vs } \\
\text { internalized morality }\end{array}$ & 78.2 & 91.4 & 13.2 \\
\hline $\begin{array}{c}\text { Balanced information processing vs } \\
\text { internalized morality }\end{array}$ & 53.1 & 71.6 & 18.5 \\
\hline Work engagement & $\begin{array}{l}\text { Unrestricted } \\
\text { model } \\
(13 \mathrm{GL})\end{array}$ & $\begin{array}{l}\text { Restricted model } \\
\quad(14 \text { GL) }\end{array}$ & \\
\hline
\end{tabular}




\begin{tabular}{|c|c|c|c|}
\hline Vigor vs dedication & 43.7 & 136.7 & 93.0 \\
\hline Vigor vs absorption & 24.6 & 121.7 & 97.1 \\
\hline Dedication vs absorption & 25.9 & 89.2 & 63.3 \\
\hline Organizational citizenship behavior & $\begin{array}{c}\text { Unrestricted } \\
\text { model } \\
(26 \text { GL })\end{array}$ & $\begin{array}{l}\text { Restricted model } \\
\quad(27 \mathrm{GL})\end{array}$ & \\
\hline $\begin{array}{l}\text { Organizational citizenship behavior } \\
\text { directed to individuals vs } \\
\text { Organizational citizenship behavior } \\
\text { directed to the organization }\end{array}$ & 62.0 & 156.8 & 94.8 \\
\hline Motivation for work & $\begin{array}{c}\text { Unrestricted } \\
\text { model } \\
(13 \mathrm{GL})\end{array}$ & $\begin{array}{l}\text { Restricted model } \\
\quad(14 \text { GL) }\end{array}$ & \\
\hline $\begin{array}{l}\text { Protection and security needs vs } \\
\text { social and belonging needs }\end{array}$ & 76.5 & 112.5 & 36.0 \\
\hline $\begin{array}{l}\text { Protection and safety needs vs self- } \\
\text { esteem needs }\end{array}$ & 98.2 & 111.1 & 12.9 \\
\hline $\begin{array}{l}\text { Protection and security needs vs self- } \\
\text { actualization needs }\end{array}$ & 110 & 213.1 & 103.1 \\
\hline $\begin{array}{c}\text { Social and belonging needs vs self- } \\
\text { esteem needs }\end{array}$ & 11.6 & 105.3 & 93.7 \\
\hline
\end{tabular}

Source: Created by the authors using the results from the study.

It should be noted that, when running the model in the first instance, it was not adjusted exhaustively and parsimoniously to the data; therefore, the modification indices and the content of the items were reviewed to improve the fit of the model, and the decision was made to exclude some items. Table 6 shows the fit indices obtained by an estimate made with maximum likelihood (ML), which indicates a satisfactory fit.

Table 6. Structural model fit indices

\begin{tabular}{cc}
\hline Index & Value \\
\hline Chi squared & 191.01 \\
Gl & 57 \\
SRMR & 0.063 \\
CFI & 0.901 \\
RMSEA & 0.076 \\
GFI & 0.951 \\
AGFI & 0.902 \\
CMIN/Gl & 3.21 \\
\hline
\end{tabular}

Source: Created by the authors using the results from the study.

For the evaluation of the structural model, each of the items was added to obtain a single indicator for each dimension, as shown in Figure 2. The model shows four latent variables. "Authentic leadership" is the exogenous or independent latent variable since its behavior is not caused by the effect of another variable; that is, it is not predicted by any other variable. The variables "motivation for work," "work engagement" and "organizational citizenship behavior" are endogenous latent variables or variables that depend on other latent variables. 
Figure 2. Structural model

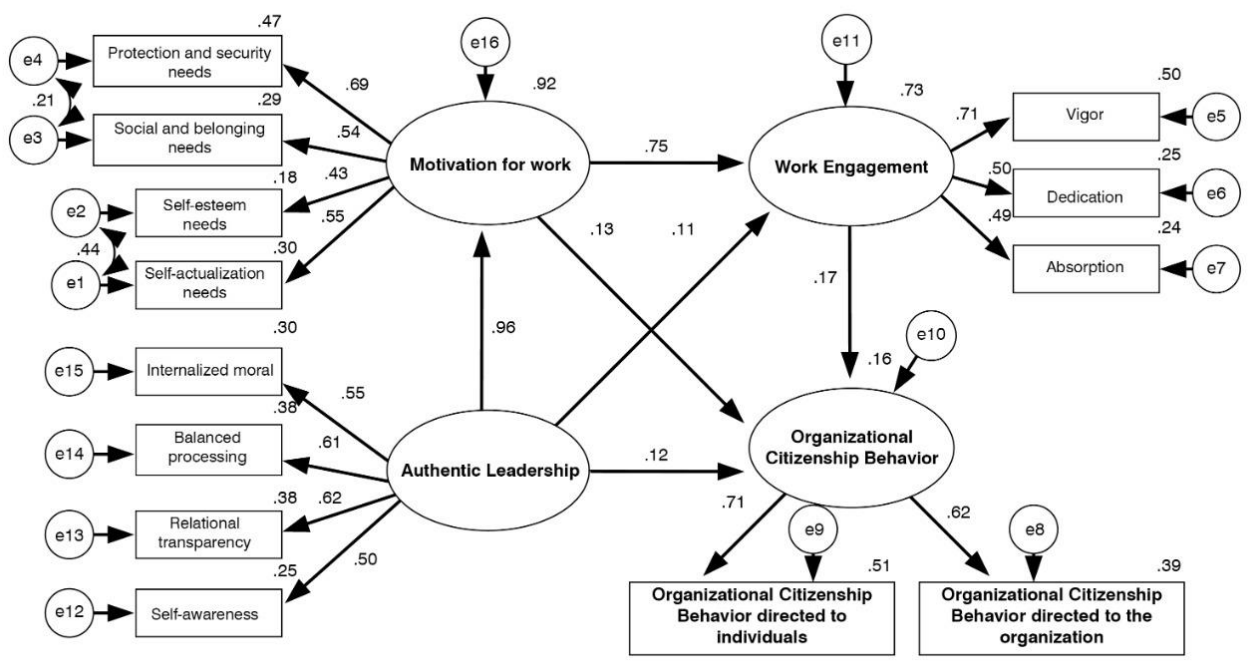

Note: Created with IBM SPSS AMOS. Model path scheme.

Source: Created by the authors using the results from the study.

Considering that the proportion of variance must have a minimum value of 0.10 for each dependent construct (Falk and Miller, 1992), it should be noted that the evaluation of the model indicates that the explained variability in motivation for work is $92 \%$, that in work engagement is $73 \%$, and that in organizational citizenship behavior is $16 \%$.

In addition to the above, as reported in Table 7, the results of the global evaluation of the sample model structure indicate that the signs of the parameters that represent the incorporated hypotheses are as expected. In other words, all the signs of the relationships among constructs in the analyzed model agree with the hypothesized relationships (H1 to $\mathrm{H} 6$ are accepted). Additionally, as shown in the same table, all the standardized estimates of the parameters show acceptable and statistically significant coefficients at $\mathrm{p}<0.001$. Moreover, the variance explained for motivation for work and work engagement is considered necessary; in turn, the variance explained for organizational citizenship behavior must be considered carefully.

Table 7. Evaluation of the structural model

\begin{tabular}{|c|c|c|c|c|}
\hline Parameter & $\lambda$ & $R^{2}$ & Hyp. & Decision \\
\hline \multirow[t]{2}{*}{$\begin{array}{c}\text { Authentic leadership } \rightarrow \text { work } \\
\text { motivation }\end{array}$} & $0.96^{* * *}$ & & $\mathrm{H} 2$ & Accept \\
\hline & & 0.92 & & \\
\hline $\begin{array}{c}\text { Authentic leadership } \rightarrow \text { work } \\
\text { engagement }\end{array}$ & $0.11^{* * *}$ & & H1 & Accept \\
\hline \multirow[t]{2}{*}{$\begin{array}{c}\text { Labor motivation } \rightarrow \text { labor } \\
\text { commitment }\end{array}$} & $0.75^{* * *}$ & & H6 & Accept \\
\hline & & 0.73 & & \\
\hline
\end{tabular}




\begin{tabular}{|c|c|c|c|c|}
\hline $\begin{array}{c}\text { Authentic leadership } \rightarrow \text { citizenship } \\
\text { behavior }\end{array}$ & $0.12^{* * *}$ & & H3 & Accept \\
\hline $\begin{array}{c}\text { Labor motivation } \rightarrow \text { citizenship } \\
\text { behavior }\end{array}$ & $0.13^{* * *}$ & & H5 & Accept \\
\hline $\begin{array}{c}\text { Work commitment } \rightarrow \text { citizenship } \\
\text { behavior }\end{array}$ & $0.17 * * *$ & & H4 & Accept \\
\hline & & 0.16 & & \\
\hline
\end{tabular}

Note: $* * * p<0.001 ; \lambda=$ standardized estimate; Hyp. = research hypothesis.

Source: Created by the authors using the results from the study.

Furthermore, Table 8 contains the aggregate effects (direct, indirect, and total effects) on endogenous variables. The results presented above account for the different routes that make up the structural model. In terms of total effects, it is noted that these can be relevant and statistically significant; $\mathrm{p}<0.001$.

Nomological validity is also known as a hypothesis or theoretical validity and implies observing the association or relationship between the construct under study and another construct (Adcock and Collier, 2001). In this order, these results constitute essential evidence that the proposed conceptual framework is supported by the data and confirms the nomological validity of the constructs that make up the model.

Table 8. Decomposition of the structural effects

\begin{tabular}{lccc}
\hline \multicolumn{1}{c}{ Effects } & Direct & Indirect & Total \\
\hline $\begin{array}{l}\text { Effects on work motivation } \\
\text { Authentic leadership }\end{array}$ & 0.96 & & $0.96^{* * *}$ \\
Effects on work engagement & & & \\
Authentic leadership & 0.11 & 0.72 & $0.83^{* * *}$ \\
Work motivation & 0.75 & & $0.75^{* * *}$ \\
Effects on citizenship behavior & & & \\
Authentic leadership & 0.12 & 0.26 & $0.38^{* * *}$ \\
$\quad$ Work motivation & 0.13 & 0.13 & $0.26^{* * *}$ \\
Work engagement & 0.17 & & $0.17^{* * *}$ \\
\hline
\end{tabular}

Note: $* * * p<0.001$.

Source: Created by the authors using the results from the study.

The results evidence that authentic leadership (1) affects work engagement directly as well as indirectly through motivation for work and (2) affects organizational citizenship behavior directly as well as indirectly through work motivation. The model incorporates motivation as a mediating or moderating variable between leadership and work engagement and between leadership and organizational citizenship behavior. Hence, the general hypothesis is accepted, showing that the effects of authentic leadership on work engagement and organizational citizenship behavior are mediated by motivation for work.

\section{Discussion and Conclusion}

The evidence provided in this study indicates that authentic leadership positively impacts the attitudes and behavior of employees (Avolio et al., 2004). A direct, 
positive, and significant relationship is identified among the perceptions of authentic leadership factors- self-awareness, relational transparency, balanced information processing, and internalized morality in MSME managers-and the factors that characterize work engagement-vigor, dedication, and absorption-among the employees of these organizations.

These findings provide support for other empirical studies (Oh et al., 2018) regarding this relationship in the area of working life, taking into consideration the fact that the companies studied correspond to all economic sectors (Banford et al., 2012) and confirming that authentic leaders generate trust among employees by promoting work engagement (Hsieh and Wang, 2015; Wang and Hsieh, 2013) and dedication to work (Wong, Laschinger, and Cummings, 2010). This indicates a potential benefit for leaders from exhibiting authentic leadership behavior to promote work engagement in employees.

Following this order of ideas, these results confirm a direct and positive relationship between authentic leadership and motivation for work. It is assumed that employees are highly motivated by exercising authentic leadership on the satisfaction of their needs. It is found that managers as authentic leaders provide meaningful feedback to employees (Ryan and Deci, 2000), promote motivation at work as a driving force to perform the task (Gill et al., 2018), motivated by satisfying the needs of employees (Leroy et al., 2012), make employees feel that they are the authors of their work behavior by satisfying their basic needs (Gardner et al., 2005; Ilies et al., 2005) and their need for participatory security (Guerrero et al., 2014) and create a positive work environment in which employees feel motivated and sufficiently confident to exert their effort in their jobs (Liu et al., 2018). Therefore, a synergistic interaction is confirmed since the combination of authentic leadership and authentic followers is associated with higher levels of satisfaction with basic needs.

From this perspective, it should be noted that these findings indicate that there is a direct and positive relationship between authentic leadership and organizational citizenship behavior. Authentic leaders encourage behaviors in employees that allow them to develop a sense of identity with the organization, become more involved, and generate new and positive behavior without being explicitly requested to do so. Furthermore, they facilitate a fair and open work environment that directly affects employees' attitudes, producing high satisfaction, trust, engagement, and willingness to perform other role behaviors (Avolio and Gardner, 2005; Avolio et al., 2004; Luthans and Avolio, 2003). The evidence supports previous studies (Organ et al., 2006) that have concluded that authentic leaders affect employees' organizational citizenship behavior positively (Edú-Valsania et al., 2012) and promote qualified behaviors (Walumbwa et al., 2010).

Moreover, the research reveals a direct and positive relationship between work engagement and organizational citizenship behavior. As a theoretical research contribution, it evidences that work engagement plays an important role. First, it is a 
mediator between motivation for work and organizational citizenship behavior; second, it is a mediator between authentic leadership and organizational citizenship behavior. This finding is consistent with the argument presented by Salanova and Schaufeli (2008), stating that work engagement encourages personal initiative and increases proactive behavior in employees. It is also congruent with other studies showing that work engagement is positively related to organizational citizenship behavior (Wahyu, 2013). Therefore, it is concluded that the participation of employees in their work, through which they meet the formal requirements of their role, extends beyond those since they strive to carry out other activities that produce well-being. This practical well-being, according to the results of other studies (Xu et al., 2019), leads to organizational citizenship behavior through the explanatory mechanism of work engagement and generates a feeling of organizational identification in employees based on pride in and respect for the organization (Zhang et al., 2017).

The study provides evidence that motivation for work predicts organizational citizenship behavior, which denotes the effectiveness of creative ideas for the improvement of the organization; it is the product of the relevance of satisfying employees' needs. This finding is consistent with previous research (Barbuto and Story, 2011; Finkelstein and Penner, 2004; Gerhart and Fang, 2014), which has demonstrated that moving needs encourages organizational citizenship behavior since motivated employees drive productivity in organizations and impart enthusiasm and energy in their coworkers (Luthans, 2002) to achieve the desired goals (KuranchieMensah and Amponsah-Tawiah, 2016).

It should be noted that the results show that there is a direct and positive relationship between motivation for work and work engagement, which indicates consistency with other research studies (Martin, 2008). It is inferred that the organizations' employees have high levels of satisfaction with their needs, which positively influences their enthusiasm and pride in their job. The similarity of this result to those reported in other studies allows us to state that motivated employees display greater engagement in and responsibility for their roles in their performance (Dysvik and Kuvaas, 2011). In addition, it is confirmed that motivation at work is expressed by the satisfaction of employees' needs that underlie the energy, purpose, and durability of the action in the commitment (Martin et al., 2017).

Finally, it should be stated that the evidence presented in the research model obtained from the theoretical model helps us to infer that the perception of the authentic leadership components (self-awareness, relational transparency, balanced information processing, and internalized morality; Walumbwa et al., 2008) produces a positive and significant direct effect on the factors that describe work engagement vigor, dedication, and absorption (Schaufeli et al., 2002), a positive and significant direct effect on the dimensions of motivation for work, protection and security needs, social and belonging needs, self-esteem needs and self-actualization needs (Franco et al., 2002) and a positive and significant direct effect on the forms of organizational citizenship behavior, organizational citizenship behavior directed to individuals and 
organizational citizenship behavior directed to the organization (Lee and Allen, 2002). The research findings indicate that the exercising of authentic leadership as a form of behavior adopted by the managers of the organizations studied positively influences the positive, satisfactory, and work-related state of mind and fosters behaviors in employees to facilitate the functioning of the organization and the will to exercise and try to achieve the objectives of the organization.

\section{Implications}

The work environment needs to be caused by rapid technological changes denote the urgent requirement for managers as genuine leaders who can facilitate organizational efficiency and promote work engagement to ensure a reduction in deviant behavior in the workplace and an increase in behavior qualifying employees as citizens. Giving feedback as an example to improve interaction with employees and elicit behavior full of energy, enthusiasm, and pride, characterized by employee engagement, encourages employees to adopt behaviors with a sense of belonging. These findings suggest that future research should investigate how authentic leadership influences the organizational culture through the work environment.

It is essential for organizations to design and implement systematic strategies and evaluations that foster and enhance the authentic leadership of supervisors as these will provide sustained improvements in motivation for individual, group, and organizational work. The research suggested that motivation for work is driven by the behaviors of leaders who create an environment of satisfaction of employees' needs, providing them with a psychologically safe environment that promotes work engagement and organizational citizenship behavior. Future research should explore how authentic leadership influences employees' feelings of empowerment about decision control and autonomy when examining these relationships.

The study shows that employees from the enterprises under study are motivated by their work and reveals that satisfying employees' needs lead to rising work engagement and organizational citizenship behavior. Managers need to constantly evaluate employee motivation levels and put into practice strategies and resources to ensure that employees are encouraged to adopt attitudes to engage with their work and appropriate behaviors and make their work seem like a hobby for them.

\section{References:}

Adcock, R., Collier, D. 2001. Measurement validity: A shared standard for qualitative and quantitative research. American Political Science Review, 95, 529-546. doi: 10.1017 / S0003055401003100.

Al Sahi, M., Ahmad, K., Hossan, C. 2016. Authentic leadership, work engagement and organizational citizenship behaviors in petroleum company. International Journal of Productivity and Performance Management, 65(6), 811-830. https://doi.org/10.1108/IJPPM-01-2016-0023. 
Avolio, B., Gardner, W. 2005. Authentic leadership development: Getting to the root of positive forms of leadership. Leadership Quarterly, 16(3), 315-338. https://doi.org/10.1016/j.leaqua.2005.03.001.

Avolio, B., Gardner, W., Walumbwa, F., Luthans, F., May, D. 2004. Unlocking the mask: A look at the process by which authentic leaders' impact follower attitudes and behaviors. Leadership Quarterly, 15(6), 801-823. doi 10.1016/j.leaqua.2004.09.003.

Bagozzi, R., Yi, Y. 1988. On the evaluation of structural equation models. Journal of the Academy of Marketing Science, 16, 74-94. https://doi.org/10.1007/BF02723327.

Bakker, A., Schaufeli, W., Leiter, M., Taris, T. 2008. Work engagement: An emerging concept in occupational health psychology. Work \& Stress, 22(3), 187-200. https://doi.org/10.1080/02678370802393649.

Banford, M., Wong, C., Laschinger, H. 2012. The influence of authentic leadership and areas of worklife on work engagement of registered nurses. Journal of Nursing Management, 21(3), 529-540. doi: 10.1111 / j.1365-2834.2012.01399.x.

Baquero, A., Delgado, B., Escortell, R., Sapena, J. 2019. Authentic leadership and job satisfaction: A fuzzy-set qualitative comparative analysis (fsQCA). Sustainability, 11(2412), 2-16. doi: 10.3390 / su11082412.

Barbuto, J., Story, J. 2011. Work motivation and organizational citizenship behaviors: A field study. Journal of Leadership Studies, 5(1), 23-34. https://doi.org/10.1002/jls.20202.

Barrett, P. 2007. Structural equation modelling: Adjudging model fit. Personality and Individual Differences, 42, 815-824. https://doi.org/10.1016/j.paid.2006.09.018.

Belitski, M., Liversage, B. 2019. E-leadership in small and medium-sized enterprises in the developing world. Technology Innovation Management Review, 9(1), 64-74. http://doi.org/10.22215/timreview/1212.

Brown, M., Treviño, L. 2006. Ethical leadership: A review and future directions. Leadership Quarterly, 17(6), 595-616. doi: 10.1016/ j.leaqua.2006.10.004.

Byrne, B. 2010. Structural Equation Modeling with AMOS. Basic Concepts, Applications, and Programming, Second Edition, Routledge, New York. https://doi.org/10.4324/9780203805534.

Crawford, J., Dawkins, S., Martin, A., Lewis, G. 2019. Putting the leader back into authentic leadership: Reconceptualising and rethinking leaders. Australian Journal of Management, 45(1), 114-133. https://doi.org/10.1177/0312896219836460.

Creswell, J., Creswell, J. 2018. Research Design: Qualitative, Quantitative, and Mixed Methods Approaches, Fifth Edition. Los Angeles, CA, Sage.

Dávila, M., Finkelstein, M. 2010. Predicting organizational citizenship behavior from the functional analysis and role identity perspectives: Further evidence in Spanish employees. Spanish Journal of Psychology, 13(1), 277-283. doi: 10.1017 / S1138741600003851.

DeVellis, R. 2017. Scale Development: Theory and Applications, Fourth Edition. Sage, Los Angeles.

DIEE. 2019. INEC: Directorio de Empresas y Establecimientos. Quito, Ecuador.

Dysvik, A., Kuvaas, B. 2011. Intrinsic motivation as a moderator on the relationship between perceived job autonomy and work performance. European Journal of Work and Organizational Psychology, 20(3), 367-387. doi: 10.1080 / 13594321003590630.

Edú-Valsania, S., Moriano, J., Molero, F., Topa, G. 2012. Authentic leadership and its effect on employees' organizational citizenship behaviours. Psicothema, 24(4), 561-566.

Falk, R., Miller, N. 1992. A Primer for Soft Modeling, University of Akron Press, Akron. 
Finkelstein, M., Penner, L. 2004. Predicting organizational citizenship behaviors: Integrating the functional and role identity approaches. Social Behavior and Personality, 32, 383-398. https://doi.org/10.2224/sbp.2004.32.4.383.

Fowler, F. 2014. Survey Research Methods, 4 Ed. Thousand Oaks, CA, Sage. https://dx.doi.org/10.4135/9781452230184.n7.

Franco, L., Bennett, S., Kanfer, R. 2002. Health sector reform and public sector health worker motivation: A conceptual framework. Social Science \& Medicine, 54(8), 1255-1266. doi: 10.1016 / S0277-9536 (01) 00094-6.

Gardner, W., Avolio, B., Luthans, F., May, D., Walumbwa, F. 2005. Can you see the real me? A self-based model of authentic leader and follower development. Leadership Quarterly, 16(3), 343-372. doi:10.1016/j.leaqua.2005.03.003.

George, B. 2003. Authentic Leadership: Rediscovering the Secrets of Creating Lasting Value. Jossey-Bass, San Francisco.

Gerhart, B., Fang, M. 2014. Pay for (individual) performance: Issues, claims, evidence, and the role of sorting effects. Human Resource Management Review, 24(1), 41-52. https://doi.org/10.1016/j.hrmr.2013.08.010.

Giallonardo, L., Wong, C., Iwasiw, C. 2010. Authentic leadership of preceptors: Predictor of new graduate nurses' work engagement and job satisfaction. Journal of Nursing Management, 18, 993-1003. doi: 10.1111/ j.1365-2834.2010.01126.x.

Gigol, T. 2020. Influence of authentic leadership on unethical pro-organizational behavior: The intermediate role of work engagement. Sustainability, 12(1182), 1-15. https://doi.org/10.3390/su12031182.

Gill, C., Gardner, W., Claeys, J., Vangronsvelt, K. 2018. Using theory on authentic leadership to build a strong human resource management system. Human Resource Management Review, 28(3), 304-318. doi:10.1016/j.hrmr.2018.02.006.

Green, S., Lissitz, R., Mulaik, S. 1977. Limitations of coefficient alpha as an index of test unidimensionality. Educational and Psychological Measurement, 37(4), 827-838. https://doi.org/10.1177/001316447703700403.

Guerrero, S., Lapalme, M.E., Séguin, M. 2014. Board chair authentic leadership and nonexecutives' motivation and commitment. Journal of Leadership \& Organizational Studies, 22(1), 88-101. doi:10.1177/1548051814531825.

Hair, J., Babin, B., Anderson, R., Black, W. 2018. Multivariate Data Analysis, Eighth Edition. New Delhi, India, Cengage.

Harter, S., Snyder, S., Lopez, S. 2002. “Authenticity”, Handbook of Positive Psychology. London, Oxford University Press, 382-394.

Hassan, A., Ahmed, F. 2011. Authentic leadership, trust, and work engagement. International Journal of Human and Social Sciences, 6(3), 164-170.

Hassan, S., Mahsud, R., Yukl, G., Prussia, G. 2013. Ethical and empowering leadership and leader effectiveness. Journal of Managerial Psychology, 28(2), 133-146. https://doi.org/10.1108/02683941311300252.

Hsieh, C., Wang, D. 2015. Does supervisor-perceived authentic leadership influence employee work engagement through employee-perceived authentic leadership and employee trust? International Journal of Human Resource Management, 4(23), 1-22. https://doi.org/10.1080/09585192.2015.1025234.

Hu, Y., Wu, X., Zong, Z., Xiao, Y., Qu, F. 2018. Authentic leadership and proactive behavior: The role of psychological capital and compassion at work. Frontiers in Psychology, 9(2470), 1-12. https://doi.org/10.3389/fpsyg.2018.02470. 
Ilies, R., Morgeson, F., Nahrgang, J. 2005. Authentic leadership and eudaemonic well-being: Understanding leader-follower outcomes. Leadership Quarterly, 16(3), 373-394. doi: 10.1016 / j.leaqua.2005.03.002/.

Iqbal, S., Farid, T., Ma, J., Khattak, A., Nurunnabi, M. 2018. The impact of authentic leadership on organizational citizenship behaviours and the mediating role of corporate social responsibility in the banking sector of Pakistan. Sustainability, 10, 2170. doi: 10.3390 / su10072170.

Jensen, S., Luthans, F. 2006. Entrepreneurs as authentic leaders: Impact on employees' attitudes. Leadership \& Organization Development Journal, 27(8), 646-666. https://doi.org/10.1108/01437730610709273.

Joo, B., Jo, S. 2017. The effects of perceived authentic leadership and core self-evaluations on organizational citizenship behavior. Leadership \& Organization Development Journal, 38(3), 463-481. doi: 10.1108 / LODJ-11-2015-0254.

Jordan, J., Brown, M., Treviño, L., Finkelstein, S. 2013. Someone to look up to: Executivefollower ethical reasoning and perceptions of ethical leadership. Journal of Management, 39(3), 660-683. https://doi.org/10.1177/0149206311398136.

Kahn, W. 1990. Psychological conditions of personal engagement and disengagement at work. Academy of Management Journal, 33(4), 692-724. https://doi.org/10.5465/256287.

Kernis, M. 2003. Toward a conceptualization of optimal self-esteem. Psychological Inquiry, 14(1), 1-26.

Kline, R. 2016. Principles and Practice of Structural Equation Modeling, Eighth Edition. Guilford Press, New York.

Kuranchie-Mensah, E., Amponsah-Tawiah, K. 2016. Employee motivation and work performance: A comparative study of mining companies in Ghana. Journal of Industrial Engineering and Management, 9(2), 255-309. http://dx.doi.org/10.3926/jiem.1530.

Lee, K., Allen, N. 2002. Organizational citizenship behavior and workplace deviance: The role of affect and cognitions. Journal of Applied Psychology, 87(1), 131-142. https://doi.org/10.1037/0021-9010.87.1.131.

Leroy, H., Anseel, F., Gardner, W., Sels, L. 2015. Authentic leadership, authentic followership, basic need satisfaction, and work role performance: A cross-level study. Journal of Management, 41(6), 1677-1697. https://doi.org/10.1177/0149206312457822.

Leroy, H., Palanski, M., Simons, T. 2012. Authentic leadership and behavioral integrity as drivers of follower commitment and performance. Journal of Business Ethics, 107, 255-264. doi: 10.1007 / s10551-011-1036-1.

Liu, Y., Fuller, B., Hester, K., Bennett, R., Simmering, M. 2018. Linking authentic leadership to subordinate behaviors. Leadership and Organization Development Journal, 39(2), 218-233. doi: 10.1108 / LODJ-12-2016-0327.

Lloret-Segura, S., Ferreres-Traver, A., Hernández-Baeza, A., Tomás-Marco, I. 2014. El análisis factorial exploratorio de los ítems: una guía práctica, revisada y actualizada. Anales de Psicología, 30(3), 1151-1169. http://dx.doi.org/10.6018/analesps.30.3.199361.

Luthans, F. 2002. The need for and meaning of positive organizational behavior. Journal of Organizational Behavior, 23(6), 695-706. https://doi.org/10.1002/job.165.

Luthans, F., Avolio, B. 2003. Authentic leadership development. Positive Organizational Scholarship, 241, 258-273. 
Malik, A., Yamamoto, S., Haque, A., Sauerborn, R. 2018. Developing and accessing a tool to measure motivation among physicians in Lahore, Pakistan. PLoS ONE, 13(12), 117. https://doi.org/10.1371/journal.pone.0209546.

Martin, A. 2008. Motivation and engagement in diverse performance settings: Testing their generality across school, university/college, work, sport, music, and daily life. Journal of Research in Personality, 42(6), 1607-1612. doi: 10.1016 / j.jrp.2008.05.003.

Martin, A., Ginns, P., Papworth, B. 2017. Motivation and engagement: Same or different? Does it matter? Learning and Individual Differences, 55, 150-162. https://doi.org/10.1016/j.lindif.2017.03.013.

Maslach, C., Leiter, M. 1997. The Truth about Burnout. San Francisco, Jossey-Bass.

Maslach, C., Leiter, M. 2008. Early predictors of job burnout and engagement. Journal of Applied Psychology, 93(3), 498-512. doi: 10.1037 / 0021-9010.93.3.498.

Maslow, A. 1954. Motivation and Personality. New York, Harper, and Row.

Maslow, A. 1991. Motivación y personalidad, 3 Ed. Madrid, España, Díaz de Santos, S.A.

Maunno, S., Kinnunen, U., Ruokolainen, M. 2007. Job demands and resources as antecedents of work engagement: A longitudinal study. Journal of Organizational Behavior, 70(1), 149-171. https://doi.org/10.1016/j.jvb.2006.09.002.

May, D., Gilson, R., Harter, L. 2004. The psychological conditions of meaningfulness, safety and availability and the engagement of the human spirit at work. Journal of Occupational and Organizational Psychology, 77, 11-37. doi: 10.1348 / 096317904322915892.

Mayer, R., Gavin, M. 2005. Trust in management and performance: Who minds the shop while the employees watch the boss? Academy of Management Journal, 48, 874888. https://doi.org/10.2307/20159703.

McAuliffe, N., Bostain, N., Witchel, A. 2019. The relationship between authentic leadership, trust, and engagement in library personnel. Journal of Library Administration, 59(2), 1429-148. https://doi.org/10.1080/01930826.2018.1562822.

McNeely, B., Meglino, B. 1994. The role of dispositional and situational antecedents in prosocial organizational behavior: An examination of the intended beneficiaries of prosocial behavior. Journal of Applied Psychology, 79(6), 836-844. doi: 10.1037 / 0021-9010.79.6.836.

Moriano, J., Molero, F., Lévy, J.P. 2011. Liderazgo auténtico. Concepto y validación del cuestionario ALQ en España. Psicothema, 23(2), 336-341.

Oh, J., Cho, D., Hun, D. 2018. Authentic leadership and work engagement: The mediating effect of practicing core values. Leadership \& Organization Development Journal, 39(2), 276-290. doi: 10.1108 / LODJ-02-2016-0030.

Olafsen, A., Deci, E., Halvar, H. 2018. Basic psychological needs and work motivation: A longitudinal test of directionality. Motivation and Emotion, 42, 178-189. doi: 10.1007 / S11031-017-9646-2.

Organ, D. 1988. Organizational Citizenship Behavior: The Good Soldier Syndrome. Lexington, Mass, Lexington Books.

Organ, D. 2018. Organizational citizenship behavior: Recent trends and developments. Annual Review of Organizational Psychology and Organizational Behavior, 5(1), 295-306. https://doi.org/10.1146/annurev-orgpsych-032117-104536.

Organ, D., Podsakoff, P., MacKenzie, S. 2006. Organizational Citizenship Behavior: Its Nature, Antecedents, and Consequences, Sage. http://dx.doi.org/10.4135/9781452231082.

Pinder, C. 2008. Work Motivation in Organizational Behavior. New York, Psychology Press. 
Podsakoff, P., MacKenzie, S., Paine, J., Bachrach, D. 2000. Organizational citizenship behaviors: A critical review of the theoretical and empirical literature and suggestions for future research. Journal of Management, 26(3), 513-563. https://doi.org/10.1177/014920630002600307.

Rahmadani, V., Schaufeli, W., Stouten, J., Zhang, Z., Zulkarnain, Z. 2020. Engaging leadership and its implication for work engagement and job outcomes at the individual and team level: A multi-level longitudinal study. International Journal of Environmental Research and Public Health, 17(3), 1-21. doi: 10.3390 / ijerph17030776.

Ribeiro, N., Gomes, D., Kurian, S. 2018. Authentic leadership and performance: The mediating role of employees' affective commitment. Social Responsibility Journal, 14(1), 213-225. doi: 10.1108 / SRJ-06-2017-0111.

Rioux, S., Penner, L. 2001. The causes of organizational citizenship behavior: A motivational analysis. Journal of Applied Psychology, 86(6), 1306-1314. https://doi.org/10.1037/0021-9010.86.6.1306.

Ryan, R., Deci, E. 2000. Intrinsic and extrinsic motivations: Classic definitions and new directions. Contemporary Educational Psychology, 25, 54-67. https://doi.org/10.1006/ceps.1999.1020.

Šakić, A., Tandir, N. 2019. Impacto of authentic leadership style on job satisfaction: Case of Insurance sector in Bosnia and Herzegovina. International Journal of Human Resource Studies, 9(1), 299-311.

Saks, A. 2006. Antecedents and consequences of employee engagement. Journal of Managerial Psychology, 21(7), 600-619. https://doi.org/10.1108/02683940610690169.

Salanova, M., Schaufeli, W. 2008. A cross-national study of work engagement as a mediator between job resource and proactive behavior. International Journal of Human Resource Management, 19(1), 116-131. doi: 10.1080/09585190701763982.

Sashkin, M. 1996. El Cuestionario MbM Gestión por motivación, Third Edition. Retrieved from: http://horarioscentros.uned.es/archivos_publicos/qdocente_planes/676898/cuestio nariombmmaslow.pdf.

Schaufeli, W. 2013. Engaging leadership in the job demands-resources model. Career Development International, 20(5), 446-463. doi:10.1108/CDI-02-2015-0025.

Schaufeli, W. 2018. Work engagement in Europe: Relations with national economy, governance, and culture. Organizational Dynamics, 47, 99-106. https://doi.org/10.1016/j.orgdyn.2018.01.003.

Schaufeli, W., Salanova, M. 2011. Work engagement: On how to better catch a slippery concept. European Journal of Work and Organizational Psychology, 20(1), 39-46. doi: 10.1080 / 1359432X.2010.515981.

Schaufeli, W., Bakker, A. 2010. Defining and measuring work engagement: Bringing clarity to the concept. In: Bakker, A., Leiter, M. (Eds.). Work Engagement: A Handbook of Essential Theory and Research. New York, New Psychology Press, 10-24.

Schaufeli, W., Bakker, A., Salanova, M. 2006. The measurement of work engagement with a short questionnaire. A cross-national study. Educational and Psychological Measurement, 66(4), 701-716. https://doi.org/10.1177/0013164405282471.

Schaufeli, W., Salanova, M., González-Roma, V., Bakker, A. 2002. The measurement of engagement and burnout: A two sample confirmatory factor analytic approach. Journal of Happiness, 3(1), 71-92. https://doi.org/10.1023/A:1015630930326. 
Shamir, B., Eilam, G. 2005. "What's your story?” A life-stories approach to authentic leadership development. Leadership Quarterly, 16(3), 395-417. https://doi.org/10.1016/j.leaqua.2005.03.005.

Taber, K. 2018. The use of Cronbach's Alpha when developing and reporting research instruments in science education. Research in Science Education, 48, 1273-1296. doi: 10.1007 / s11165-014-9413-2.

Ursachi, G., Horodnic, I., Zait, A. 2015. How reliable are measurement scales? External factors with indirect influence on reliability estimators. Procedia Economics and Finance, 20, 679-686. https://doi.org/10.1016/S2212-5671(15)00123-9.

Wahyu, A. 2013. The relationship between employee engagement, organizational citizenship behavior, and counterproductive work behavior. International Journal of Business Administration, 4(2), 46-56. doi: 10.5430 / ijba.v4n2p46.

Walumbwa, F., Avolio, B., Gardner, W., Wernsing, T., Peterson, S. 2008. Authentic leadership: Development and validation of a theory-based measure. Journal of Management, 34(1), 89-126. doi: 10.1177 / 0149206307308913.

Walumbwa, F., Wang, P., Wang, H., Schaubroeck, J., Avolio, B. 2010. Psychological processes linking authentic leadership to follower behaviors. Leadership Quarterly, 21, 901-914. doi:10.1016/j.leaqua.2010.07.015.

Wang, D., Hsieh, C. 2013. The effect leadership on employee trust and employee engagement. Social Behavior and Personality, 41(4), 613-624. https://doi.org/10.2224/sbp.2013.41.4.613.

Williams, L., Anderson, S. 1991. Job satisfaction and organizational commitment as predictors of organizational citizenship in a non-work setting. Journal of Organizational Behavior, 1(3), 601-617. https://doi.org/10.1177/014920639101700305.

Wong, C., Laschinger, H., Cummings, G. 2010. Authentic leadership and nurses' voice behavior and perceptions of care quality. Journal of Nursing Management, 18(8), 889-900. doi: 10.1111 / j.1365-2834.2010.01113.x.

$\mathrm{Xu}$, J., Xie, B., Chung, B. 2019. Bridging the gap between affective well-being and organizational citizenship behavior: The role of work engagement and collectivist orientation. International Journal of Environmental Research and Public Health, 16(22), 1-16. doi:10.3390 / ijerph16224503.

Zhang, Y., Guo, Y., Newman, A. 2017. Identity judgements, work engagement and organizational citizenship behavior: The mediating effects based on group engagement model. Tourism Management, 61, 190-197. https://doi.org/10.1016/j.tourman.2017.01.005.

Zubair, S., Khan, M. 2018. Authentic leadership and organization citizenship behavior: A case of Pakistani electronic news media industry. Journal of Management and Business, 5(1), 16-32. doi: 10.30537 / sijmb.v5i1.11. 